\title{
The Visualization Center at Scripps Institution of Oceanography: Education and Outreach
}

\author{
D. Kilb, C. S. Keen, R. L. Newman, G. M. Kent, D. T. Sandwell, F. L. \\ Vernon, C. L. Johnson, and J. A. Orcutt
}

Cecil H. and Ida M. Green Institute of Geophysics and Planetary Physics, University of California at San Diego

\section{THE VISUALIZATION CENTER AT SCRIPPS}

Since opening in March 2002, the Visualization Center at Scripps has had more than 2,500 visitors, of which -500 were education- and outreach-related. Based upon follow-up requests and referrals, we expect these numbers to grow. The center's state-of-the-art visualization technology projects high-resolution, multidimensional images onto a $120^{\circ}$ curved Panoram ${ }^{\circledR}$ floor-to-ceiling screen $\left(8^{\prime} 6^{\prime \prime}\right.$ by $\left.28^{\prime} 4^{\prime \prime}\right)$ that immerses viewers in a virtual environment (Figure 1). The center is ideal for presenting and manipulating very large data sets to groups of up to 50 people, and the system is equipped with transmitters and LCD shutter glasses that allow stereographic 3D viewing of high-resolution data sets through a set of specialized eyeglasses (Figure 2). The lenses in the glasses flicker synchronously with the computer images at 48 frames per second, per eye, thus producing a stereo or $3 \mathrm{D}$ effect.
Multiple video streams can be simultaneously displayed, including the SGI ${ }^{\circledR}$ megadesktop, S-VHS video, DVD video, and video from a laptop computer; the user can quickly toggle between these various platforms (Kent et al., 2002). Similarly, the five-channel surround-sound audio system can be integrated through several inputs, allowing for numerous video and audio combinations. For instance, one third of the screen can display S-VHS video of damaging earthquakes, while the remaining portion of the screen can show an interactive underground 3D flight through seismicity in the regions presented in the video. Alternatively, the audio surround-sound system can be set to produce sounds of various synthetically generated earthquakes (http://quake.wr.usgs. gov/info/listen/allsounds.html), while the corresponding seismicity, topography, and seismic station locations and telemetry paths are juxtaposed on the screen with the associated seismic waves.

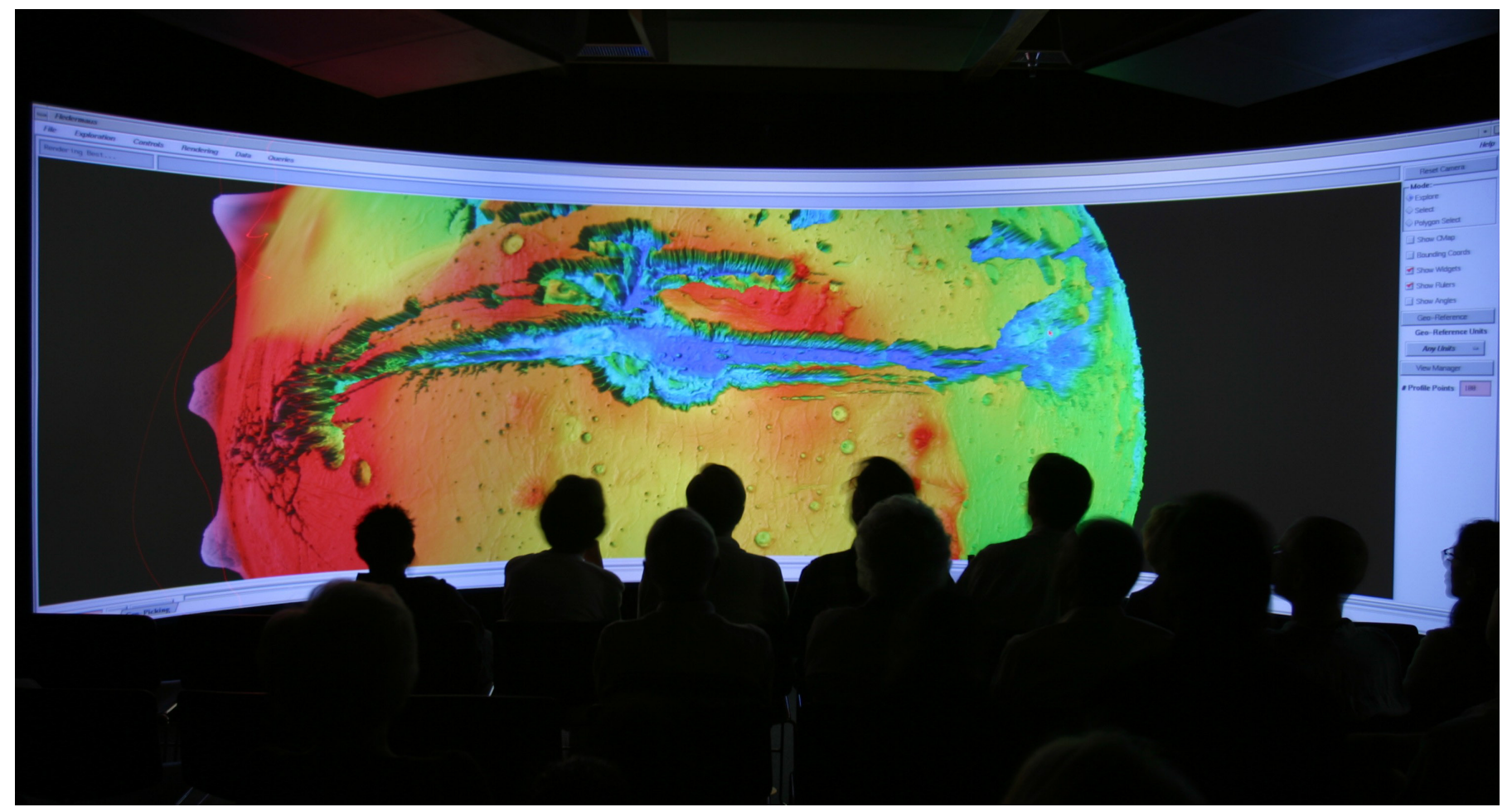

$\Delta$ Figure 1. A group of visitors in the Visualization Center at Scripps view the topography of Mars. 


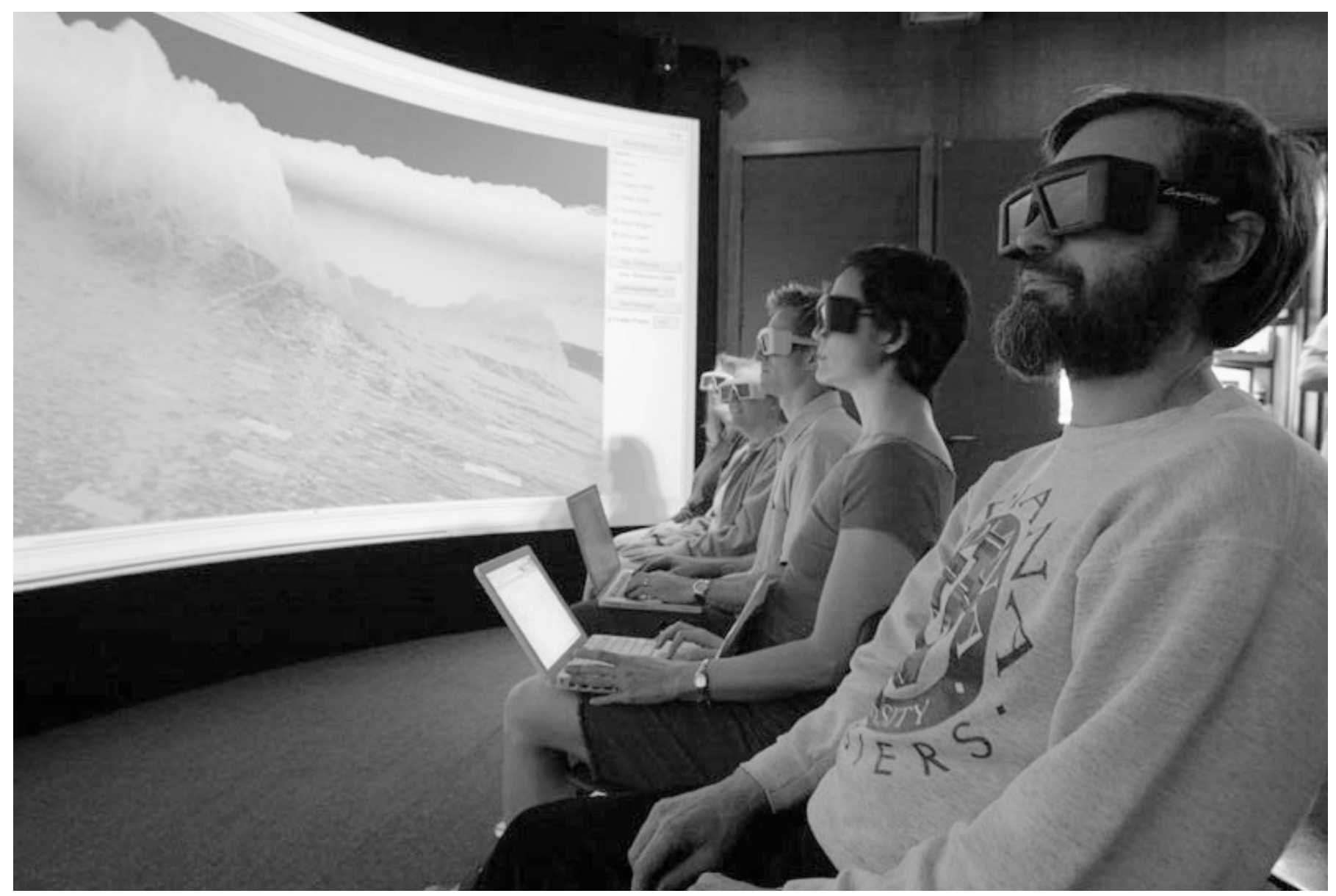

A Figure 2. Visitors to the Visualization Center at Scripps use specially designed 3D glasses to view high-resolution stereo images of the topography of southern California and station telemetry lines, along with the locations of 40,000 earthquakes that were recorded by the Anza seismic network over the last twenty years. A virtual flight through these data can be dictated on the spot by the user.

\section{EDUCATION AND OUTREACH}

Unlike many educational centers, the Visualization Center at Scripps is housed within a research institution-the Cecil H. and Ida M. Green Institute of Geophysics and Planetary Physics (IGPP) —allowing visitors to interact with geophysicists who typically do not participate in off-site education and outreach programs. We have found this to be beneficial in many ways: The visitors gain exposure to experts from multiple geophysical disciplines, the researchers gain experience discussing their science in layman's terms, and questions posed by persons outside of the geophysics discipline can lead to new avenues of discovery. For example, one visitor inquired about the "funny initial wiggle" on a seismogram that was clearly visible on the center's wall-sized screen, but not as apparent on the typical desktop monitors used by most seismologists. The relationship of this recently identified preshock to the associated mainshock is being examined (e.g., Dodge et al., 1995; Kilb and Gomberg, 1999).

In planning for future Education and Outreach uses of the center, we have established the following focus areas: (1) identifying how the center can support Earth science stan- dards for K-12 education; (2) introducing K-12 teachers to Earth science teaching modules and supplying them with the necessary tools to incorporate these modules in their classrooms; (3) placing special emphasis on educating students who have expressed an interest in Earth science, as well as underrepresented students; (4) using the high-end computer capabilities at our Visualization Center to produce Webaccessible geoscience education modules; (5) supplying schools that lack sufficient computing capabilities to use our visual objects with large-scale laminated Earth science posters that can be used in the classroom; and (6) providing the Digital Library for Earth System Education (DLESE) with visual objects for distribution through their national portal (http:// www.dlese.org/). To assure that these goals are attainable we have teamed with a curriculum development specialist, SIO Earth scientists, K-12 teachers, education/outreach professionals, computer scientists, and a cognitive scientist.

For our informal science presentations, we tailor our discussions to fit the interests of our visitors yet make every attempt to discuss research currently underway. In a typical hour, visitors "fly" through the topography of Mars; the bathymetry, seismic reflectivity, and fault structure of Lake 
Tahoe; southern California's topography and seismicity $(\sim 40,000$ earthquakes) accompanied by real-time seismic waveforms recorded by the Anza seismic network (see Kilb et al., 2003); and seismicity from around the world $(-384,000$ earthquakes from the PDE catalog).

Depending upon the interest of our audience, we can explore more specific topics. For example, we depict each earthquake recorded by the Anza seismic network (http:// www.eqinfo.ucsd.edu) in southern California as a point that is color-coded according to its time of occurrence; from these images clusters of similarly colored points can be identified as either mainshock/aftershock sequences, induced seismicity (e.g., from quarries), or earthquake swarms. Visitors learn that, unlike mainshock/aftershock sequences, induced earthquakes have very shallow depths $(<5 \mathrm{~km})$. Other concepts/ topics that we highlight include the accurate locations of microearthquakes in California (as determined from waveform cross correlation; Kilb and Rubin, 2002), detailed bathymetry of the global ocean basins and its tectonic implications (based on ship soundings and inversion of satellite altimetry data; Smith and Sandwell, 2002), and interferometric synthetic aperture radar (InSAR) maps of the surface deformation following the M 7.1 1999 Hector Mine, California, earthquake (Sandwell et al., 2000; Fialko et al., 2002). We discuss the basic scientific questions being addressed (e.g., is earthquake size predictable; using estimated fault dimensions to determine what the associated seismic hazards are for a region; is there evidence for an ocean on Mars, and if so how extensive might it have been) and outline techniques that researchers at SIO are implementing to gain a better understanding of a variety of problems (e.g., Hartse et al., 1994; Haase et al., 1995; Johnson et al., 1997; Sandwell et al., 1997; Babcock et al., 1998; Price and Sandwell, 1998; Kent et al., 2000; Kilb et al., 2000; Lyons et al., 2000; Fialko et al., 2001; Miller et al., 2001; Sandwell and Smith, 2001; Hardebeck and Shearer, 2002; Kilb and Rubin, 2002; Shearer, 2002; Kent et al., 2003; Kilb, 2003).

\section{K-12 Education}

To date, our youngest group of visitors was Ms. Beaudet's 6th grade class from the Nazareth School in San Diego. We introduced these students to the concept of supercomputers, seismology, the topography of Mars, the formation of the lake bottom of Lake Tahoe, and Space-to-your-Face (an interactive application that seamlessly allows exploration of multiresolution images from space) (http://siovizcenter.ucsd.edu/ news_events.shtml).

As part of the NSF IT OptIPuter (Optical IP computer) project (http://www.calit2.net/news/2002/9-25-optiputer. html), we are involved in a field-based education and outreach program through the Preuss School, which is a San Diego City Charter School for low-income, first-generation collegebound students, grades $6-12$, located on the UCSD campus (http://preuss.ucsd.edu/). In collaboration with curriculum writers, Preuss School teachers, and various geoscience researchers, we are assisting in the development of an Earth science curriculum at the 8 th grade level. Our role in this effort involves developing geophysical data visualizations to be used as tools in observational inquiry-based learning. For example, the students can "fly" through computer-generated images of seismic data from around the globe and use patterns in seismicity to identify tectonic plate boundaries. They can also use the depth of the seismicity to identify the different plate boundary types (e.g., subduction zone boundaries have deeper seismicity than strike-slip boundaries). Students can learn to question the robustness of the data by overlaying seismicity and station locations to determine if regions of minimal seismic activity are truly areas of seismic quiescence or merely an artifact of sampling. Interactions such as these will, over the next five years, result in the development of portable learning units (visual objects) for general Web-based distribution through our Web site and/or through the DLESE portal. As part of this project, these visual objects will also be integrated into classrooms in targeted school districts in San Diego, Houston, and Chicago. In this way, the full nature of the visual objects can be viewed and explored in 3D stereo on inexpensive systems such as the GeoWall (http:// geowall.geo.lsa.umich.edu).

\section{Southern California Earthquake Center: Summer Interns and Teacher Programs}

A scientific collaboration evolved from a tour of our facility by Southern California Earthquake Center (SCEC) summer undergraduate interns. Interns Sara Whipple and Leonard Jimenez helped facilitate an exchange of data sets between San Diego State University (SDSU), SCEC, and IGPP that included detailed 3D fault models developed by SCEC's crustal fault model group (http://structure.harvard.edu/cfma/), roads in California, the continental USA outline, fault traces, and city names. Additionally, Sara Whipple and Jeff Sale from SDSU visited the Visualization Center at Scripps on multiple occasions to develop QuickTime ${ }^{\circledR}$ movies and produce data sets beneficial to our interests as well as their projects for the Seismic Safety Commission (http://www.seismic.ca.gov/). Some of the resulting geophysical visualization projects, which primarily focus on southern California, are available online (http://www.siovizcenter.ucsd.edu/streaming/).

We are collaborating with Incorporated Research Institutions for Seismology (IRIS), SCEC, USGS, SDSU, and the Birch Aquarium at Scripps to develop one-day teacher training workshops that incorporate visualizations created at the Visualization Center at Scripps. The goal of these workshops is to "provide a direct connection between scientists and developers of earthquake education resources and those who use these resources in the classroom" (SCEC Communication, Education and Outreach [CEO] program annual meeting report, 2002). The workshops, taught in tandem by SIO researchers, SCEC, and USGS education personnel, will be held at the Visualization Center at Scripps in Spring 2003 to offer $\mathrm{K}-12$ teachers hands-on opportunities to work with earthquake activities developed primarily by IRIS. We have augmented existing materials with visualizations produced in 
the Visualization Center at Scripps and are working with science teachers and local public school science administrators to generate interest in the workshops. If there are significant interest and resources, we hope to offer the workshop annually, as well as to extend our efforts to include $\mathrm{K}-12$ classroom field trips to the Visualization Center at Scripps.

\section{Teach for America}

In the summer of 2002, SIO Assistant Professor Catherine Johnson teamed with Teach for America (http://www. teachforamerica.org/) corps member MacGregor Campbell for two months at SIO. MacGregor is a 7 th grade math teacher at Davis Middle School in Compton, California. He generously used his summer break to develop math modules based on Earth and planetary science. These modules are available online (http://mahi.ucsd.edu/johnson/mathjourney/ introduction.html) and were purposely designed for teachers in schools with minimal or no computer equipment. Educators nationwide can download the modules from their home computers and then bring the information to the students using nothing but chalk, a chalkboard, and at times an overhead projector. Part of MacGregor's time was spent in the Visualization Center at Scripps developing QuickTime movies of the topography of Mars (http://siovizcenter.ucsd.edu/ streaming/) and familiarizing himself with other available data sets such as the Earth's topography, global seismicity, and the bathymetry of Lake Tahoe. Based on his experience in the center, MacGregor comments, "I am excited to share with my students the information I have learned and the experiences I have had in the center working with SIO researchers. I hope some day each of my students will have similar opportunities that make scientific research easy to understand and, most importantly, fun."

\section{Graduate Student Research using the Visualization Center at Scripps}

To educate IGPP graduate students about data visualization, we held a graduate student competition at the Visualization Center at Scripps on 6 September 2002 (http://www. siovizcenter.ucsd.edu/news_events/2002/09/06.shtml). Prior to the competition we offered several informal classes introducing the center's hardware and software, as well as data types suitable for visualization. These classes were followed by individual tutorials with students who expressed an interest in using visualizations to understand and present their research projects. The competitors' presentations covered a range of topics, including the topography of Mars, active tectonics in Lake Tahoe, electromagnetic methods, seismicity from around the globe, and the topography of Baja California. Some entries were simple projects, such as showing the extraordinary expanse of the Valles Marineris canyon system on Mars by draping a political map of the United States on it, while other, more complex projects were based on software development for research and image generation that required many weeks of preparation (e.g., http://schwehr.org/viz02/).
The four judges for the event included scientists with a range of backgrounds as well as one nonscientist. All the judges were impressed with the quality of the presentations. The event was successful in introducing IGPP graduate students to high-end visualization technology. Further annual competitions are planned, incorporating students across science curriculum groups at the Scripps Institution of Oceanography campus; it is hoped this will allow students to improve their understanding of multidimensional scientific problems and play an integral part in extending their knowledge of visualization technology.

The Visualization Center at Scripps has also been used to teach graduate classes in tectonics, time series analysis, seismology, mathematical methods, geophysical data analysis, geophysical inverse theory, and geodynamics. In a recent class, for example, Dr. Peter Shearer used the wall-sized screen display to demonstrate how to use the Seismic Analysis Code (SAC) computer software program. Seeing first-hand how the program worked greatly familiarized the students with the computer program-much more so than the typically used paper handouts.

Some graduate students have opted to use the Visualization Center at Scripps for their Ph.D. defenses. Most students divide the wall-sized screen into three sections, simultaneously displaying movies, equations, interpretations, and descriptions of their work. In one case, in preparation for a defense, the memory and speed of the SGI ${ }^{\circledR} 3400$ Onyx computer reduced the rendering time of a movie of pattern development in Arctic soils by an order of magnitude (this is related to a recent cover of the journal Science: http:// www.igpp.ucsd.edu/ne/2003/01/29.html).

\section{Partnership with the Birch Aquarium at Scripps}

Multiple education and outreach programs have been developed through a partnership with the Birch Aquarium at Scripps (http://aquarium.ucsd.edu/). These efforts included hosting a component of the Southern California regional competition of the National Ocean Sciences Bowl (NOSB) and two components of the Expanding your Horizons workshops, which are geared to enhance 6th through 10th grade girls' exposure to science, mathematics, engineering, and technology (http://www.sdsa.org/EYH/). Another weekend, gifted students from the Junior Science and Humanities Program, an undertaking that recognizes high school students for outstanding achievement in experimentation and original research in the sciences, visited the aquarium to learn about the Earth and discuss geophysical and oceanographic science. At the Visualization Center at Scripps, where the students spent a portion of their visit, they were introduced to basic geophysical techniques, including what a seismogram looks like, determination of the approximate location of an earthquake (i.e., near the station that has the earliest first seismic arrival), and more challenging concepts. To introduce the concept of dynamic triggering of earthquakes (Harris, 1998; Kilb et al., 2000; Wyss and Wiemer, 2000; Freed et al., 2001; Power $e t$ al., 2001) we took a virtual flight across the topogra- 


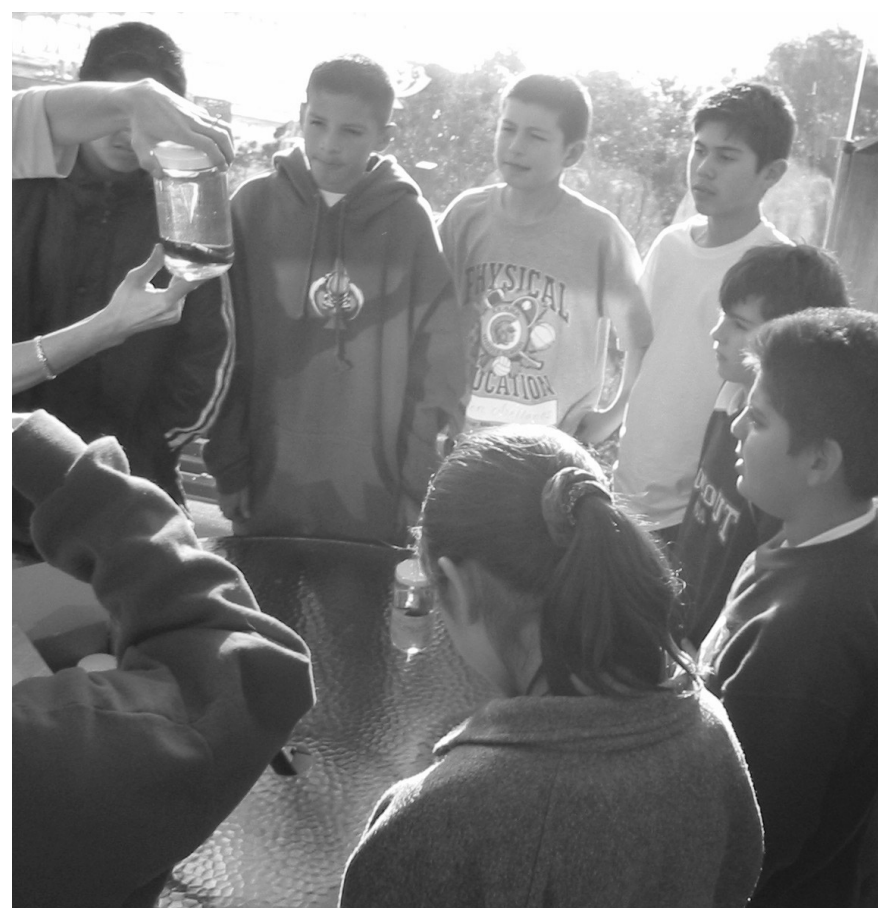

$\Delta$ Figure 3. Dr. Cheryl Peach from the Birch Aquarium at Scripps discusses aspects of the ocean environment, has the students identify kelp beds (visible from the balcony of the Visualization Center at Scripps), and shows the students specimens of meso- and bathypelagic fish.

phy of the western USA from the epicenter of the southern California 1992 Landers earthquake to locations of documented remote aftershock triggering, such as Cedar City, Utah; Boise, Idaho; and Yellowstone, Montana (Hill et al., 1993).

Trips to the Visualization Center at Scripps were also included in Aquarium programs designed for Aquatic Adventures' high school mentors and middle school youth. Aquatic Adventures (http://www.aquaticadventures.org) is a private, nonprofit science education organization dedicated to providing free programs in Earth and ocean sciences to students at underserved San Diego schools. This visit included identifying the kelp beds that are visible from the balcony of the Visualization Center at Scripps (Figure 3). To measure the student's retention, a pre-/postvisit evaluation was conducted by Shara Fisler, Executive Director of Aquatic Adventures. The results showed a marked improvement in the students' knowledge about Earth science (on the previsit evaluation the average score was $11 / 21$; on the postvisit evaluation the average score was 20/21).

\section{Television-based Modules}

The Visualization Center at Scripps has been spotlighted in local and national television news programs. Some programs have had specific focuses; for example, the National Geographic Channel interviewed researchers about natural disasters pertaining to earthquakes and earthquake-generating seiche waves near Lake Tahoe (Kent et al., 2003). Other programs are more general, such as a local San Diego television crew production of three -10 -minute interviews with Dr. Graham Kent, in which the purpose of the Visualization Center at Scripps and its capabilities were discussed.

A production company called INTELECOM based in Pasadena is producing a 26-part community college curriculum and PBS series on oceanography called "The Endless Voyage." They have interviewed scientists at all of the major oceanographic institutions and research universities on a wide variety of topics, ranging from the dynamics of the Earth's interior to ocean basin structure, and from physical oceanography to biological oceanography. To provide graphics to accompany the scientific narration, Dr. David Sandwell produced seven animations using the technology at the Visualization Center at Scripps. These modules will be used for both PBS broadcasts and computer-based Earth-science instruction. The animations display the Earth with the ocean drained and provide a tour of all of the major seafloor spreading ridges, subduction zones, and hotspot seamount chains. These tours provide graphical evidence for the structures on the ocean floor that were created and modified by global plate tectonic activity over the past 200 million years of Earth history.

We are currently working in conjunction with SDSU Professor Dr. Pat Abbott, who is in the process of creating a broadcast-quality video for the award-winning "Written in Stone" series (http://www-rohan.sdsu.edu/ wis). The next video, Shake, Rattle, and Grow: A View of the Growth of the Topography in Los Angeles, will emphasize the development of an earthquake through fault histories and plate tectonics to demonstrate how the Los Angeles landscape was formed by the same processes that sometimes interrupt our daily livesearthquakes. Our contribution to this project will be a virtual tour through the topography of southern California. Our virtual tour will mimic the route of a helicopter flight, employing a gyro-stabilized Wescan camera system. Unlike true flight, our virtual tour can make the surface of the Earth transparent so that we can see the locations of earthquakes in Southern California and their correlation with the topography in the region, as well as the mapped faults. By integrating true flight with virtual flight, we can speculate as to what the surface topography might be able to tell us about seismicity at depth (e.g., mountainous regions typically correlate with seismicity).

\section{Research/Education from Spatially Different Locations}

One long-range goal of the Visualization Center at Scripps is to continue collaborating with Cal-(IT) ${ }^{2}$, SDSU, and diverse high-tech companies (e.g., SGI, TeraBurst, Cox Communications) toward building an infrastructure that enables synchronous sharing of immersive environments, including the next generation of visualization hardware, as well as ensuring that these technologies work seamlessly with the end users' systems. Our center and the partner center at SDSU are linked via Cox Communications' 44-mile, 10-gigabit-per-second optical-fiber network, making these centers a prototype for how educators in different physical locations can interact. 
Groups at both institutions are able to send and receive data and images simultaneously, allowing collaboration on the analysis of large 3D geophysical data sets in real-time. This network is facilitated by TeraBurst Networks' WAVS ${ }^{\circledR}$ (Wide Area Visualization Solution), which is based on a high-performance, optical networking platform (OC-192). This technology enables the transmission of massive amounts of data between multiple locations and is the only technology available that enables video, audio, and data to be transmitted simultaneously and synchronously over a wide-area optical network to spatially remote centers. Given that network speeds are doubling every nine months, this level of interactivity will be available throughout the U.S. in three to five years, enabling educators from multiple institutions to view extremely large data sets simultaneously.

\section{UTILIZATION OF VISUALIZATION OBJECTS DEVELOPED IN THE VISUALIZATION CENTER AT SCRIPPS}

\section{Alternative Visualization Systems}

The visualization systems used by educators can, at times, limit presentation resources. Computer memory and computer speed are two of the primary constraints. To cope with this problem, educators resort either to limiting the spatial or temporal range of their data, or forfeiting simultaneous display of multiple data sets (e.g., combining bathymetry, seismicity, and seismic cross-sections). One alternative is to use computers with large amounts of memory and speed to render snapshots, images, and movies that are too big for other systems, and then export smaller end products to more commonly used computer systems. For educators, one of the best current options is to display these end products on the portable PC-based GeoWall (http://www.geowall.org), which consists of two data projectors that overlap their projections on a $5^{\prime}$ by $4^{\prime}$ screen, forming a "side by side" stereo image. We have teamed with the developers of GeoWall to make some of the data products we develop on our system viewable on the GeoWall system. For interactive data manipulation, the freeware iView3D (http://www.ivs.unb.ca/products/iview3d/) viewer can be used to view visual objects created using IVS' Fledermaus software (http://www.ivs.unb.ca/). These solutions allow educators access to high-quality products at no or minimal cost.

\section{Seismological Freeware Programs and Web-accessible Information}

To encourage further development of our visitors' geophysical knowledge, we introduce a number of freeware programs during demonstrations in the Visualization Center at Scripps and illustrate how easy they are to download to a laptop. We do this by displaying the desktop of our laptop on our large screen, so that all visitors can view the installation and operating procedures. One of the most popular programs is the Seismic Eruption computer program developed by Alan L. Jones. A link to this program, as well as to other relevant resources, can be found on our Web site (http://www.siovizcenter.ucsd.edu/library/links/index.shtml).

\section{QuickTime Movies}

QuickTime movies of our data products can be viewed by the general public from our real-time streaming server (http:// www.siovizcenter.ucsd.edu/streaming/). We primarily create these movies using IVS' Fledermaus software (http:// www.ivs.unb.ca/), which has a simple feature that allows the user to delimit a flight path through a data scene (which can be a conglomeration of multiple data sets), smooth any kinks in the flight path, and render a movie based on separate image snapshots. The resulting QuickTime movies are ideal for use in classrooms from grade school through college, as well as for viewing by the general public. Another avenue of distribution is through online journals, such as Science, Journal of Geophysical Research, and Nature, that publish QuickTime movies as part of journal articles (e.g., Kent et al., 2000).

The movies we generate provide easy-to-use material for introductory Earth science classes in institutions that do not have high-end visualization systems. Some of the movies we produce in the Visualization Center at Scripps incorporate large amounts of data that are impossible to render on smaller systems, yet the resulting final file sizes of the movies are manageable for even a laptop. This reduces the hardware costs for a "visualization system" to the cost of a low-end laptop $(-\$ 1,500)$.

The movies can also be used in the interim while educators determine the interests and needs of their institutions in terms of visualization systems. End users such as Gary Patterson, Information Services Director with the Center for Earthquake Research and Information at the University of Memphis, have used our QuickTime movies in presentations in university and government environments. Patterson has employed the movies in workshops to demonstrate to educators the direction in which visual-based learning products are headed. This has generated interest from his coworkers, who plan to use the QuickTime movies in their classes. We expect the distribution of the movies to be rapid and widespread to many geophysical researchers, as well as for use in education and public outreach programs.

\section{EARTHQUAKE RESPONSE, SEISMIC SAFETY, AND HOMELAND SECURITY}

Visits to our center from California Emergency Response personnel have led to an open exchange of ideas with respect to emergency planning procedures. For example, during a visit to the Visualization Center at Scripps by top emergency response management teams, we demonstrated how SIO seismologists record and locate earthquakes and discussed the possibility of making these tools available to emergency responders. We plan to continue to work with these groups to develop real-time earthquake information that can assist with emergency efforts. 
The Visualization Center at Scripps has housed a number of media responses to relatively large earthquakes in the San Diego area. Response to the 31 October 2001 Anza $M_{L} 5.1$ earthquake included an interactive 3D flight over the topography of southern California on our wall-sized screen, real-time display of aftershocks recorded by the Anza seismic network (http://eqinfo.ucsd.edu), and media interviews with Drs. Frank Vernon and Graham Kent. A similar response after the 22 February 2002 Calexico $M_{L} 5.3$ earthquake included a virtual flight through the seismicity of southern California, with a focus on the seismicity near the mainshock epicenter.

The Education Center on Computational Science and Engineering (ECCSE; http://www.edcenter.sdsu.edu/) has begun a three-way collaboration with SPAWAR and IGPP to establish a "Civil Visualization Network" in an effort to equip our experts with high-speed collaborative decision support systems to educate our students and the general public on crisis mitigation, disaster preparedness, and emergency response. This network will leverage the optical fiber connection already existing between the SDSU Immersive Visualization Center and the Visualization Center at Scripps. We aim to develop examples of collaborative research and education to demonstrate the value of such technologies.

\section{SCHEDULING AN EDUCATIONAL OR RESEARCH VISIT}

Researchers and staff at the Visualization Center at Scripps make every effort to accommodate all requests from the community to visit and use our center. Currently two days per year are reserved for visits from the general public on a firstcome, first-served basis (e-mail vizinfo@ucsd.edu for more information). We are in the process of developing a costrecovery rate structure for visits to and use of the center by educators, researchers, and emergency response personnel.

\section{SUMMARY}

The immersive environment of the Visualization Center at Scripps, coupled with the presentation of current seismological research, has great education and outreach potential. Since its March 2002 opening, the Visualization Center at Scripps has had more than 2,500 visitors, and numerous virtual visitors have explored our Web pages, which include streaming QuickTime movies of geophysical data, tutorials on how to use SGI/Mac/Windows ${ }^{\circledR}$ visualization software, and examples of visualizations developed by SIO researchers and faculty members (http://siovizcenter.ucsd.edu/library. shtml). We will continue to expand the use of the Visualization Center at Scripps for K-12 and informal education, and to use the center to supply geophysical data sets, movies, and research results to as large a group of educators as possible. Our goal is to develop more sustained $\mathrm{K}-12$ educational programs and to generate assessments of the center's programs and the educational products created at the Center. $\mathbf{\Sigma}$

\section{ACKNOWLEDGMENTS}

The success of the Visualization Center at Scripps is due to a group effort put forth by many volunteers. We would like to thank Jeff Babcock, MacGregor Campbell, Yuri Fialko, Noah Knowles, Steve Miller, David Pierce, Jeff Sale, and Sara Whipple for volunteering their time. We also thank Chris Garrod and Kitty Haak for their attention to details that are essential to the smooth operation of our system and to our visitors' enjoyment. The Center was funded independently of federal support and included funding from the Cecil $\mathrm{H}$. and Ida M. Green Foundation for Earth Sciences, the California Institute for Telecommunications and Information Technology, the Scripps Institution of Oceanography, and the San Diego Supercomputer Center. This research was supported by NSF under award ANI-0225642 and by ONR under award N00014-97-1-0154.

\section{REFERENCES}

Babcock, J., A. Harding, G. Kent, and J. Orcutt (1998). An examination of along-axis variation of magma chamber width and crustal structure on the East Pacific Rise between 13 degrees 30' N and 12 degrees 20' N, Journal of Geophysical Research 103, 30,45130,467 .

Dodge, D. A., G. C. Beroza, and W. L. Ellsworth (1995). Foreshock sequence of the 1992 Landers, California, earthquake and its implications for earthquake nucleation, Journal of Geophysical Research 100, 9,865-9,880.

Fialko, Y., D. Sandwell, D. Agnew, M. Simons, P. Shearer, and B. Minster (2002). Deformation on nearby faults induced by the 1999 Hector Mine earthquake, Science 297, 1,858-1,862.

Fialko, Y., M. Simons, and D. Agnew (2001). The complete (3-D) surface displacement field in the epicentral area of the 1999 Mw7.1 Hector Mine earthquake, California, from space geodetic observations, Geophysical Research Letters 28, 3,063-3,066.

Freed, A. M. and J. Lin (2001). Delayed triggering of the 1999 Hector Mine earthquake by viscoelastic stress transfer, Nature $\mathbf{4 1 1}$ 180-183.

Haase, J., P. Shearer, and R. Aster (1995). Constraints on temporal variations in velocity near Anza, California, from analysis of similar event pairs, Bulletin of the Seismological Society of America 85, 194-206.

Hardebeck, J. L. and P. M. Shearer (2002). A new method for determining first-motion focal mechanisms, Bulletin of the Seismological Society of America 92, 2,264-2,276.

Harris, R. A. (1998). Introduction to special section: Stress triggers, stress shadows, and implications for seismic hazard, Journal of Geophysical Research 103, 24,347-24,358.

Hartse, H., M. Fehler, R. Aster, J. Scott, and F. Vernon (1994). Smallscale stress heterogeneity in the Anza seismic gap, southern California, Journal of Geophysical Research 99, 6,801-6,818.

Hill, D. P., P. A. Reasenberg, A. Michael, W. J. Arabasz, G. C. Beroza, D. S. Brumbaugh, J. N. Brune, R. Castro, S. D. Davis, D. M. dePolo, W. L. Ellsworth, J. Gomberg, S. Harmsen, L. House, S. M. Jackson, M. J. S. Johnston, L. Jones, R. Keller, S. Malone, L. Munguia, S. Nava, J. C. Pechmann, A. Sanford, R. W. Simpson, R. B. Smith, M. Stark, M. Stickney, A. Vidal, A. Walter, V. Wong, and J. Zollweg (1993). Seismicity remotely triggered by the magnitude 7.3 Landers, California, earthquake, Science $\mathbf{2 6 0}$ $1,617-1,623$.

Johnson, C. L., S. C. Solomon, and M. Simons (1997). Global and regional resolution studies of Magellan gravity data: Implications 
for inferring lithospheric thickness, Lunar and Planetary Sciences XXVIII, 667-668.

Kent, G. M., J. M. Babcock, N. W. Driscoll, A. J. Harding, G. G. Seitz, J. A. Dingler, J. V. Gardner, C. R. Goldman, A. C. Heyvaert, R. Karlin, L. A. Mayer, C. W. Morgan, and R. C. Richards (2003). Modern deformation across Lake Tahoe as measured from submerged paleo-shorelines and faults, Nature (to be submitted).

Kent, G. M., D. L. Kilb, J. A. Orcutt, and E. G. Frost (2002). Collaborative visualization in Earth and ocean sciences, Margins Newsletter 8, 1-2.

Kent, G. M., S. C. Singh, A. J. Harding, M. C. Sinha, V. Tong, P. J. Barton, R. Hobbs, R. White, S. Bazin, and J. Pye (2000). Evidence from three-dimensional seismic reflectivity images for enhanced melt supply beneath mid-ocean-ridge discontinuities, Nature 406, 614-618.

Kilb, D. (2003). A strong correlation between induced peak dynamic Coulomb stress change from the 1992 M7.3 Landers, California, earthquake and the hypocenter of the 1999 M7.1 Hector Mine, California, earthquake, Journal of Geophysical Research 108, 2012, doi:10.1029/2001JB000678.

Kilb, D. and J. Gomberg (1999). The initial subevent of the 1994 Northridge, California, earthquake: Is earthquake size predictable?, Journal of Seismology 3, 409-420.

Kilb, D., J. Gomberg, and P. Bodin (2000). Earthquake triggering by dynamic stresses, Nature 408, 570-574.

Kilb, D., R. L. Newman, F. L. Vernon , J. A. Eakins, L. Ziegler, J. Bowen, and J. Otero (2003). Education and outreach based on data from the Anza seismic network in southern California, Seismological Research Letters 74, 522-528.

Kilb, D. and A. M. Rubin (2002). Relocated microearthquakes of the Mt. Lewis $M_{L} 5.7$, California, earthquake sequence: Implications of diverse fault orientations, Journal of Geophysical Research 107, 2294, doi:10.1029/2001JB000149.

Lyons, S. N., Y. Bock, and D. T. Sandwell (2000). Near-field crustal deformation and creep characteristics in the Imperial Valley, Eos, Transactions of the American Geophysical Union 81, F1562.
Miller, S. P., J. Helly, A. Koppers, and P. Brueggeman (2001). SIOExplorer: Digital Library Project, in An Ocean Odyssey, MTS/IEEE Oceans 2001 Proceedings 4, 2,288-2,296.

Power, J. A., S. C. Moran, S. R. McNutt, S. D. Stihler, and J. J. Sanchez (2001). Seismic response of the Katmai volcanoes to the 6 December 1999 magnitude 7.0 Karluk Lake earthquake, Alaska, Bulletin of the Seismological Society of America 91, 57-63.

Price, E. and D. T. Sandwell (1998). Small-scale deformations associated with the 1992 Landers, California, earthquake mapped by synthetic aperture radar interferometry phase gradients, Journal of Geophysical Research 103, 27,001-27,016.

Sandwell, D. T., C. L. Johnson, F. Bilotti, and J. Suppe (1997). Driving forces for limited tectonics on Venus, Icarus 129, 232-244.

Sandwell, D., T. Sichoix, D. Agnew, Y. Bock, and J.-B. Minster (2000). Near real-time radar interferometry of the Mw 7.1 Hector Mine Earthquake, Geophysical Research Letters 27, 3,101-3,104.

Sandwell, D. T. and W. H. F. Smith (2001). Bathymetric estimation, in L. L. Fu and A. Cazenale (editors), Satellite Altimetry and Earth Sciences, Academic Press, 441-457.

Shearer, P. M. (2002). Parallel fault strands at 9-km depth resolved on the Imperial Fault, southern California, Geophysical Research Letters 29(14), doi: 10.1029/2002GL015302.

Smith, B. and D. Sandwell (2002). Coulomb stress accumulation along the San Andreas fault system, Journal of Geophysical Research 108, doi: 10.1029/2002JB001831.

Wyss, M. and S. Wiemer (2000). Change in the probability for earthquakes in Southern California due to the Landers magnitude 7.3 earthquake, Science 290, 1,334-1,338.

Cecil H. and Ida M. Green Institute of Geophysics and Planetary Physics UCSD MS 0225

La Jolla, CA 92093-0225

Telephone: $+1-858-882-4607$

Fax: +1-858-534-6354

E-mail:dkilb@epicenter.ucsd.edu 